\title{
What Is the Exposome and How It Can Help Research on Air Pollution
}

\author{
Paolo Vineis ${ }^{1}$ \\ Received: 21 September 2018 / Accepted: 2 November 2018 / Published online: 13 November 2018 \\ (C) The Author(s) 2018
}

\begin{abstract}
The concept of "exposome" has been introduced to allow an empowerment of environmental research, by improving measurements of external stressors and of internal biological changes, the latter taking advantage of advancements in high-throughput technologies called "omics." Here, I discuss the application of the exposome concept and techniques to the field of air pollution. I address some open issues in air pollution science, such as the effects of components in a mixture, low doses, biological pathways, and a meaningful interpretation of omic findings in the context of "hallmarks" of disease. The exposome may represent the next frontier for the regulation of low-dose environmental contaminants.
\end{abstract}

Keywords Air pollution $\cdot$ Nanoparticles $\cdot$ Epigenetics $\cdot$ Metabolomics $\cdot$ Mixtures $\cdot$ Pathways $\cdot$ Hallmarks

The identification of hazardous environmental pollutants is complex, particularly in relation to chronic, noncommunicable diseases. The main contributors to this complexity are the diversity of hazards that may exist, the typically low levels of environmental contaminants, long latency periods, and largely unknown modes of action. The unraveling of environmental causes of disease is also limited by the technical difficulties in defining, and accurately measuring exposures, and by considerable spatial, temporal, and intraindividual variations. The complex and partially unknown interaction with underlying genetic and other factors that modulate susceptibility and response to environmental exposures further complicates the process of delineating and understanding environmental hazards. To address such difficulties, the concept of the "exposome" was proposed, initially by Wild [1], with more recent detailed development in relation to its application to population-based studies ([2]). The original concept was expanded by others, particularly Rappaport and Smith [3] who functionalized the exposome in terms of chemicals detectable in biospecimens. The exposome concept refers to the totality of exposures from a variety of sources including, but not limited to, chemical agents, biological

Paolo Vineis

p.vineis@imperial.ac.uk

1 MRC-PHE Centre for Environment and Health, Imperial College, Norfolk Place W2 1PG, London, UK agents, radiation, and psychosocial components from conception onwards, over a complete lifetime, and offers a conceptual leap in studying the role of the environment in human disease [2-4].

Epidemiological studies have estimated that a large proportion of deaths worldwide can be attributed to air pollution [5, 6]. The most recent estimate is of a total of 9 million deaths per year due to PM2.5 exposure alone, encompassing both indoor and outdoor air pollution [5]. The vast majority of these deaths occur in low-income countries. Such epidemiological estimates are based on a number of assumptions and rely upon information that can be at times inaccurate or incomplete. The main assumption is that the attribution to air pollutants of a number of diseases is causal. Assessing causality is not straightforward in epidemiology, and implies that the statistical associations that are observed are biologically plausible. One way to increase biological plausibility and lend credibility to epidemiological studies is to complement them with molecular markers, in particular with "omic" research. "Exposome" research - as defined above - consists at least in part in the use of omic technologies in addressing a number of biological questions, for example in air pollution research.

Here, I show how a specific project, Exposomics (funded under the EU FP7 program) $[4,7]$ has contributed to the science of health effects of air pollution by answering some key questions. Through the integration of a total of 14 studies, the project refined exposure assessment based on the external (personal exposure monitoring) and the internal (omics) components of the exposome. Five omics (transcriptomics, adductomics, metabolomics, epigenomics, and proteomics) 
were tested for their association with exposure and health effects using mainly untargeted approaches in up to 3000 samples.

\section{Findings on Ultrafine Particles}

Ultrafine particles (UFP) exposure has been less studied than exposure to larger particles so far. UFP have characteristics that may lead to higher toxicity, including their extremely small size (allowing them to reach deeper into the tissues) and higher surface-to-mass ratio (that facilitates adhesion of larger amounts of hazardous materials). Whether or not this translates into increased risks of respiratory or cardiovascular diseases in humans remains to be clarified.

In Exposomics, we conducted a study on adult onset asthma (AOA) $(n=73)$ with non-asthmatics as the reference group $(n=115)$. Assessment of exposure to UFP was based on multi-area land use regression (LUR) models derived from specific-measurement campaigns. We found a strong association of UFP exposure with AOA [8]. The odds ratios were $1.80(95 \%$ CI $1.26,2.55)$ for an increase in particle number concentration (PNC) by 5000 particles $/ \mathrm{cm}^{3}$, and $1.73(95 \% \mathrm{CI}$ $1.27,2.36)$ for an increase in lung-deposited surface area (LDSA) by $10 \mu \mathrm{m}^{2} / \mathrm{cm}^{3}$. $\mathrm{PM}_{2.5}$ and $\mathrm{NO}_{2}$ did not show a significant association with AOA.

\section{Investigation of Pathways Leading to Asthma and Cardiovascular Disease}

In a study on cardio- and cerebro-vascular disease (CCVD) in Exposomics, we aimed to investigate the involvement of oxidative stress and inflammation in the causal chain, and to identify intermediate biomarkers that are associated retrospectively with the exposure and prospectively with the disease. We designed a case-control study on CCVD nested in a cohort of 18,982 individuals from the EPIC-Italy study [9]. We measured air pollution, inflammatory biomarkers, and wholegenome DNA methylation in blood collected up to 17 years before the diagnosis. The study sample included all the incident CCVD cases among former- and never-smokers that arose in the cohort during the follow-up. We identified enrichment of altered DNA methylation in "ROS/glutathione/cytotoxic granules" and "cytokine signaling" pathways-related genes, associated with both air pollution and with CCVD risk. Interleukin-17 was associated with higher exposure to $\mathrm{NO}_{2}$ $(P=0.0004), \mathrm{NO}_{\mathrm{x}}(P=0.0005)$, and CCVD risk $(\mathrm{OR}=1.79$; CI 1.04-3.11; $P=0.04$ comparing extreme tertiles). Our findings indicate that chronic exposure to air pollution can lead to oxidative stress, which in turn activates inflammatory responses mainly involving the "cytokine signaling" pathway, leading in turn to increased risk of CCVD. Our research suggests that inflammatory proteins and DNA methylation alterations can be detected several years before CCVD diagnosis in blood samples.

Epidemiologic evidence indicates in fact common risk factors, including air pollution exposure, for respiratory and cardiovascular diseases. This may imply the involvement of common perturbed molecular pathways. The goal of a further investigation within Exposomics was to find intermediate metabolites or metabolic pathways in two cohorts (EPIC and SAPALDIA), that could be associated with both air pollutants and health outcomes, thus shedding light on mechanisms and reinforcing causality (Jeong et al., 2018). We measured untargeted metabolomics in two independent case-control studies nested in cohorts on adult-onset asthma (AOA, same as before) and cardio-cerebrovascular diseases (CCVD, same as before). We have identified several metabolic pathways that potentially mediate the effect of air pollution on health outcomes. Among those, perturbation of Linoleate metabolism pathway was associated with all three-air pollution exposure, AOA, and CCVD. Our results suggest that common pathway perturbations may occur as a consequence of chronic exposure to air pollution leading to increased risk for both $\mathrm{AOA}$ and CCVD.

\section{Study of Mixtures}

Air pollution is a mixture of compounds that can be in a gaseous or particle phase. One of the obvious practical questions of research on health is whether components in a mixture act separately (via different metabolic or molecular pathways) or they impact common pathways. Omics investigations from Exposomics have shown that both cases are realistic depending on the mixture we consider. First, we considered air pollutants from the Oxford Street randomized cross-over trial [10] in which volunteers were exposed to high (Oxford Street, London) or low (Hyde Park) levels of air pollution. Both for RNA (mRNA and miRNA, the latter involved in post-transcriptional gene expression modulation) and for metabolites from mass spectrometry the different components of air pollution gave rise to signals that did not overlap, suggesting that each pollutant follows a different metabolic or molecular pathway to exert its effects $[10,11]$. An opposite example comes from water (Piscina study in Exposomics). In this case, we enrolled swimmers (volunteers) to swim in a normal Barcelona pool contaminated by chlorinated or brominated disinfection by-products $([11,12])$. In this example, there seems to be a broad overlap between miRNA and, respectively, MS metabolomic signals across five different disinfection by-products. This is biologically plausible since the five compounds had very similar chemical composition. Therefore, we can expect different health impacts of components of the air pollution mixtures, but similar effects of water contaminated 
by disinfection by-products (for statistical methods of mixture analysis see [13]).

\section{Low Doses}

There is no evidence that common exposures such as air pollution or secondhand smoking show a threshold in their action. For example, in the ESCAPE network, we found that mortality increases below the current "acceptable" limits for particulate set by WHO ([14]). The very establishment of lowdose effects requires very careful epidemiological designs, extremely accurate individual exposure assessment, good characterization of confounders, and very large sample sizes. One potential explanation of low or very low dose effects is the combination of different exposures conferring acquired susceptibility, plus genetic predisposition.

The existence of low-dose effects implies that we should be able to detect molecular changes at those levels of exposure. Support for this is starting to increase through the application of omics in investigations of low-dose exposures. For example, we have found that the levels of exposure to $\mathrm{PM}_{10}$ experienced in utero from four different European areas (Italy, Belgium rural, Greece, Spain) influence cord blood metabolomic signals (unpublished). This can be perceived at low levels of exposure to air pollution, though we also noted that the effects were stronger in the areas with higher levels of pollution than in rural areas with lower levels.

\section{Multiple Effects of Urban Air Pollution on Molecular and Metabolic Markers: Comparison with "Key Characteristics of Carcinogens"}

In Exposomics, we had three categories of studies:

1. Experimental short-term studies (Oxford Street, TAPAS, Piscina)

2. Personal exposure monitoring studies (PEM)

3. Long-term exposure studies such as those on CCVD and asthma described above.

Table 1 Main findings (FDR significance) of Exposomics studies by category

\begin{tabular}{|c|c|c|}
\hline Study and reference & Pollutant & Molecules afffected \\
\hline \multicolumn{3}{|l|}{ 1. Experimental short term studies } \\
\hline Oxford Street (1) & TRAP & 54 miRNA \\
\hline Oxford Street (2) & NO2 & Acyl-carnitine, carnitine shuttle \\
\hline TAPAS (2) & PM2.5 & Lyso-PC \\
\hline \multicolumn{3}{|l|}{ 2. Personal exposure monitoring panels } \\
\hline PEM (3) & PM2.5 & methylation of KNDC1 and FAM50B, increase of CCL22 \\
\hline PEM (4) & PM2.5. & 61 mi RNA (no overlap with (1)) \\
\hline \multicolumn{3}{|l|}{ 3. Long-term studies } \\
\hline \multirow[t]{2}{*}{ CCVD in EPIC (5) } & NO2 & IL-8, IL-17, EGF, Eotaxin \\
\hline & PM2.5 & $\begin{array}{l}\text { Methylation of cytokine signaling and reactive oxygen } \\
\text { species/glutathione/cytotoxic pathways }\end{array}$ \\
\hline Asthma and CCVD in EPIC-Sapaldia (6) & PM2.5 & $\begin{array}{l}\text { Linoleate (regulator of IL-8) } \\
\text { Carnitine shuttle } \\
\text { Glycosphingolipids }\end{array}$ \\
\hline Children (7) & PM10 & $\begin{array}{l}\text { GABA-ergic synapse, P53 } \\
\text { signaling, NOTCH1 }\end{array}$ \\
\hline ESCAPE cohorts (8) & TRAP & $\begin{array}{l}\text { IL-8 in combined cohorts } \\
\text { Methylation of MTMR2, AHCYL2 }\end{array}$ \\
\hline
\end{tabular}

TRAP, traffic-related air pollution; PEM, personal exposure monitoring; CCVD, cerebro- and cardio-vascular disease

(1) $[10]$

(2) Van Veldhoven et al., submitted

(3) [15]

(4) Unpublished

(5) [16]

(6) Jeong et al., 2018

(7) [17]

(8) [18] 
Table 2 Key characteristics of carcinogens (from [22])

1. Is electrophilic or can be metabolically activated Parent compound or metabolite with an electrophilic structure (e.g., epoxide, quinone), formation of DNA and protein adducts

2. Is genotoxic DNA damage (DNA strand breaks, DNA-protein cross-links, unscheduled DNA synthesis), intercalation, gene mutations, cytogenetic changes (e.g., chromosome aberrations, micronuclei)

3. Alters DNA repair or causes genomic instability alterations of DNA replication or repair (e.g., topoisomerase II, base-excision, or double-strand break repair) equivalent to Hallmark-increased genome instability and mutation rate

4. Induces epigenetic alterations DNA methylation, histone modification, microRNA expression

5. Induces oxidative stress oxygen radicals, oxidative stress, oxidative damage to macromolecules (e.g., DNA, lipids)

6. Induces chronic inflammation elevated white blood cells, myeloperoxidase activity, altered cytokine and/or chemokine production equivalent to Hallmark inflammation

7. Is immunosuppressive decreased immunosurveillance, immune system dysfunction equivalent to Hallmark evading immune destruction

8. Modulates receptor-mediated effects receptor in/activation (e.g., ER, PPAR, AhR) or modulation of endogenous ligands (including hormones)

9. Causes immortalization inhibition of senescence, cell transformation equivalent to Hallmark enabling replicative immortality

10. Alters cell proliferation, cell death, or nutrient supply increased proliferation, decreased apoptosis, changes in growth factors, energetics and signaling pathways related to cellular replication or cell cycle control, angiogenesis. Equivalent to five hallmarks, namely sustaining proliferative signaling, evading growth suppressors, resisting cell death, inducing angiogenesis and reprogramming of energy metabolism

Table 1 shows the main results we have found so far in the published papers and some still unpublished findings. The purpose of this paragraph is to address consistency of the findings across omic platforms and across study designs.

There are several lessons that can be drawn. First, DNA methylation results do not seem to replicate across studies. This is not entirely surprising because- - with exceptions - only few genes have been found to be consistently hypo- or hyper-methylated in relation to strong carcinogens such as tobacco smoke (notably AHRR, [19]). As Table 1 shows, signals that replicate across studies in Exposomics are IL-8 in three studies (including Linoleate that is involved in IL-8 activation), carnitine shuttle in 2 studies, and Lyso-PC in two studies (Table 1). As indicated above, these signals suggest that pathways commonly perturbed after exposure to air pollution involve inflammation and oxidative stress.

A research program within the exposome community is currently trying to reconcile the pathways that have been empirically identified with "hallmarks" of disease or key characteristics of toxicants. For example, López-Otín et al. [20] proposed nine 'hallmarks of aging,' including primary hallmarks (genome instability, telomere attrition, epigenetic alterations, loss of proteostasis), antagonistic hallmarks (deregulated nutrient sensing, mitochondrial dysfunction, and cellular senescence), and integrative hallmarks (stem cell exhaustion and altered intercellular communication). Similarly, hallmarks of cancer have been proposed, partly overlapping with those for aging [21]. Others have suggested to classify the key characteristics of carcinogens into 10 categories as described in Table 2 [22].

When in Exposomics (Table 1), we looked for signals corresponding to hallmarks of cancer or key characteristics of carcinogens, we detected significant perturbation of the following categories: miRNA expression; cytokine signaling (inflammation); reactive oxygen species (oxidative stress); glycosphingolipids (apoptosis, cell growth, senescence, cell cycle control); NOTCH1 (cell cycle control); carnitine shuttle; and acyl-carnitines (oxidative stress). Inflammation, oxidative stress, and miRNA are also involved in respiratory and cardiovascular diseases. Oxidative stress pathways are compatible with our observations on the oxidative potential of air pollutants as measured in filters [23].

Thus, though still very preliminary, this approach looks like a promising avenue to make sense of the multitude of signals emerging from omic investigations. Looking at pathways and pathway perturbation is a way to confer biological plausibility to observations and to increase statistical power.

\section{Conclusions}

Exposomics is one of the first investigations on the exposome in environmental research. Some results are promising, particularly in the investigation of mixtures, and in the identification of biological pathways perturbed by air pollution that lead to diseases in different organs. Much work still needs to be done for a more thoughtful interpretation of such pathways, for example, using the paradigm of "hallmarks" of disease as I propose here.

Funding Information This work has been supported by the Exposomics (European Commission FP7 Grant number 308610) grant to PV.

\section{Compliance with Ethical Standards}

The authors declare that they have no competing interests. 
Open Access This article is distributed under the terms of the Creative Commons Attribution 4.0 International License (http:// creativecommons.org/licenses/by/4.0/), which permits unrestricted use, distribution, and reproduction in any medium, provided you give appropriate credit to the original author(s) and the source, provide a link to the Creative Commons license, and indicate if changes were made.

\section{References}

1. Wild, C.P.: Complementing the genome with an "exposome": the outstanding challenge of environmental exposure measurement in molecular epidemiology. Cancer Epidemiol. Biomark. Prev. 14(8), 1847-1850 (2005)

2. Wild, C.P.: The exposome: from concept to utility. Int. J. Epidemiol. 41(1), 24-23 (2012)

3. Rappaport, S.M., Smith, M.T.: Environment and disease risks. Science. 330(6003), 460-461 (2010)

4. Vineis, P., Chadeau-Hyam, M., Gmuender, H., Gulliver, J., Herceg, Z., Kleinjans, J., Kogevinas, M., Kyrtopoulos, S., Nieuwenhuijsen, M., Phillips, D.H., Probst-Hensch, N., Scalbert, A., Vermeulen, R., Wild, C.P., EXPOsOMICS Consortium: The exposome in practice: design of the EXPOsOMICS project. Int. J. Hyg. Environ. Health. 220(2 Pt A), 142-151 (2017). https://doi.org/10.1016/j.ijheh.2016. 08.001

5. Burnett R, Chen H, Szyszkowicz M, Fann N, Hubbell B, Pope CA 3rd, Apte JS, Brauer M, Cohen A, Weichenthal S, Coggins J, Di Q, Brunekreef B, Frostad J, Lim SS, Kan H, Walker KD, Thurston GD, Hayes RB, Lim CC, Turner MC, Jerrett M, Krewski D, Gapstur SM, Diver WR, Ostro B, Goldberg D, Crouse DL, Martin RV, Peters P, Pinault L, Tjepkema M, van Donkelaar A, Villeneuve PJ, Miller AB, Yin P, Zhou M, Wang L, Janssen NAH, Marra M, Atkinson RW, Tsang H, Quoc Thach T, Cannon JB, Allen RT, Hart JE, Laden F, Cesaroni G, Forastiere F, Weinmayr G, Jaensch A, Nagel G, Concin H, Spadaro JV. Global estimates of mortality associated with long-term exposure to outdoor fine particulate matter. Proc. Natl. Acad. Sci. U. S. A. 2018

6. Cohen, A.J., Brauer, M., Burnett, R., Anderson, H.R., Frostad, J., Estep, K., Balakrishnan, K., Brunekreef, B., Dandona, L., Dandona, R., Feigin, V., Freedman, G., Hubbell, B., Jobling, A., Kan, H., Knibbs, L., Liu, Y., Martin, R., Morawska, L., Pope 3rd, C.A., Shin, H., Straif, K., Shaddick, G., Thomas, M., van Dingenen, R., van Donkelaar, A., Vos, T., Murray, C.J.L., Forouzanfar, M.H.: Estimates and 25-year trends of the global burden of disease attributable to ambient air pollution: an analysis of data from the Global Burden of Diseases Study 2015. Lancet. 389(10082), 1907-1918 (2017)

7. Turner, M.C., Vineis, P., Seleiro, E., Dijmarescu, M., Balshaw, D., Bertollini, R., Chadeau-Hyam, M., Gant, T., Gulliver, J., Jeong, A., Kyrtopoulos, S., Martuzzi, M., Miller, G.W., Nawrot, T., Nieuwenhuijsen, M., Phillips, D.H., Probst-Hensch, N., Samet, J., Vermeulen, R., Vlaanderen, J., Vrijheid, M., Wild, C., Kogevinas, M., EXPOsOMICS Consortium: EXPOsOMICS: final policy workshop and stakeholder consultation. BMC Public Health. 18(1), 260 (2018). https://doi.org/10.1186/s12889-018-5160-z

8. Jeong, A., Fiorito, G., Keski-Rahkonen, P., Imboden, M., Kiss, A., Robinot, N., Gmuender, H., Vlaanderen, J., Vermeulen, R., Kyrtopoulos, S., Herceg, Z., Ghantous, A., Lovison, G., Galassi, C., Ranzi, A., Krogh, V., Grioni, S., Agnoli, C., Sacerdote, C., Mostafavi, N., Naccarati, A., Scalbert, A., Vineis, P., ProbstHensch N; EXPOsOMICS Consortium: Perturbation of metabolic pathways mediates the association of air pollutants with asthma and cardiovascular diseases. Environ Int. 119:334-345 (2018). https:// doi.org/10.1016/j.envint.2018.06.025

9. Fiorito, G., Polidoro, S., Dugué, P.A., Kivimaki, M., Ponzi, E., Matullo, G., Guarrera, S., Assumma, M.B., Georgiadis, P., Kyrtopoulos, S.A., Krogh, V., Palli, D., Panico, S., Sacerdote, C., Tumino, R., Chadeau-Hyam, M., Stringhini, S., Severi, G., Hodge, A.M., Giles, G.G., Marioni, R., Karlsson Linnér, R., O'Halloran, A.M., Kenny, R.A., Layte, R., Baglietto, L., Robinson, O., McCrory, C., Milne, R.L, Vineis, P. Social adversity and epigenetic aging: a multi-cohort study on socioeconomic differences in peripheral blood DNA methylation. Sci Rep. 7(1):16266. (2017). https:// doi.org/10.1038/s41598-017-16391-5

10. Krauskopf, J., Caiment, F., van Veldhoven, K., Chadeau-Hyam, M., Sinharay, R., Chung, K.F., Cullinan, P., Collins, P., Barratt, B., Kelly, F.J., Vermeulen, R., Vineis, P., de Kok, T.M., Kleinjans, J.C.: The human circulating miRNome reflects multiple organ disease risks in association with short-term exposure to traffic-related air pollution. Environ. Int. 113, 26-34 (2018). https://doi.org/10. 1016/j.envint.2018.01.014

11. van Veldhoven, K., Keski-Rahkonen, P., Barupal, D.K., Villanueva, C.M., Font-Ribera, L., Scalbert, A., Bodinier, B., Grimalt, J.O., Zwiener, C., Vlaanderen, J., Portengen, L., Vermeulen, R., Vineis, P., Chadeau-Hyam, M., Kogevinas, M.: Effects of exposure to water disinfection by-products in a swimming pool: a metabolomewide association study. Environ. Int. 111, 60-70 (2018). https:// doi.org/10.1016/j.envint.2017.11.017

12. Espín-Pérez, A., Font-Ribera, L., van Veldhoven, K., Krauskopf, J., Portengen, L., Chadeau-Hyam, M., Vermeulen, R., Grimalt, J.O., Villanueva, C.M., Vineis, P., Kogevinas, M., Kleinjans, J.C., de Kok, T.M.: Blood transcriptional and microRNA responses to short-term exposure to disinfection by-products in a swimming pool. Environ. Int. 110, 42-50 (2018). https://doi.org/10.1016/j. envint.2017.10.003

13. Jain P, Vineis P, Liquet B, Vlaanderen J, Bodinier B, van Veldhoven K, Kogevinas M, Athersuch TJ, Font-Ribera L, Villanueva CM, Vermeulen R, Chadeau-Hyam M. A multivariate approach to investigate the combined biological effects of multiple exposures. J. Epidemiol. Commun. Health. 2018. doi: https://doi.org/10.1136/ jech-2017-210061.

14. Beelen, R., Raaschou-Nielsen, O., Stafoggia, M., Andersen, Z.J., Weinmayr, G., Hoffmann, B., Wolf, K., Samoli, E., Fischer, P., Nieuwenhuijsen, M., Vineis, P., Xun, W.W., Katsouyanni, K., Dimakopoulou, K., Oudin, A., Forsberg, B., Modig, L., Havulinna, A.S., Lanki, T., Turunen, A., Oftedal, B., Nystad, W., Nafstad, P., De Faire, U., Pedersen, N.L., Östenson, C.G., Fratiglioni, L., Penell, J., Korek, M., Pershagen, G., Eriksen, K.T., Overvad, K., Ellermann, T., Eeftens, M., Peeters, P.H., Meliefste, K., Wang, M., Bueno-de-Mesquita, B., Sugiri, D., Krämer, U., Heinrich, J., de Hoogh, K., Key, T., Peters, A., Hampel, R., Concin, H., Nagel, G., Ineichen, A., Schaffner, E., Probst-Hensch, N., Künzli, N., Schindler, C., Schikowski, T., Adam, M., Phuleria, H., Vilier, A., Clavel-Chapelon, F., Declercq, C., Grioni, S., Krogh, V., Tsai, M.Y., Ricceri, F., Sacerdote, C., Galassi, C., Migliore, E., Ranzi, A., Cesaroni, G., Badaloni, C., Forastiere, F., Tamayo, I., Amiano, P., Dorronsoro, M., Katsoulis, M., Trichopoulou, A., Brunekreef, B., Hoek, G.: Effects of long-term exposure to air pollution on natural-cause mortality: an analysis of 22 European cohorts within the multicentre ESCAPE project. Lancet. 383(9919), 785-795 (2014)

15. Mostafavi, N., Vermeulen, R., Ghantous, A., Hoek, G., ProbstHensch, N., Herceg, Z., Tarallo, S., Naccarati, A., Kleinjans, J.C.S., Imboden, M., Jeong, A., Morley, D., Amaral, A.F.S., van Nunen, E., Gulliver, J., Chadeau-Hyam, M., Vineis, P., Vlaanderen, J.: Acute changes in DNA methylation in relation to $24 \mathrm{~h}$ personal air pollution exposure measurements: a panel study in four European countries. Environ. Int. 120, 11-21 (2018) 
16. Fiorito, G., Vlaanderen, J., Polidoro, S., Gulliver, J., Galassi, C., Ranzi, A., Krogh, V., Grioni, S., Agnoli, C., Sacerdote, C., Panico, S., Tsai, M.Y., Probst-Hensch, N., Hoek, G., Herceg, Z., Vermeulen, R., Ghantous, A., Vineis, P., Naccarati, A.: EXPOsOMICS consortium. Oxidative stress and inflammation mediate the effect of air pollution on cardio- and cerebrovascular disease: a prospective study in nonsmokers. Environ. Mol. Mutagen. 59(3), 234-246 (2018). https://doi.org/10.1002/em.22153

17. Plusquin, M., Guida, F., Polidoro, S., Vermeulen, R., RaaschouNielsen, O., Campanella, G., Hoek, G., Kyrtopoulos, S.A., Georgiadis, P., Naccarati, A., Sacerdote, C., Krogh, V., Bas Bueno-de-Mesquita, H., Monique Verschuren, W.M., SayolsBaixeras, S., Panni, T., Peters, A., Hebels, D.G.A.J., Kleinjans, J., Vineis, P., Chadeau-Hyam, M.: DNA methylation and exposure to ambient air pollution in two prospective cohorts. Environ. Int. 108, 127-136 (2017). https://doi.org/10.1016/j.envint.2017.08.006.

18. Mostafavi, N., Vlaanderen, J., Chadeau-Hyam, M., Beelen, R., Modig, L., Palli, D., Bergdahl, I.A., Vineis, P., Hoek, G., Kyrtopoulos, S.A., Vermeulen, R.: Inflammatory markers in relation to long-term air pollution. Environ. Int. 81, 1-7 (2015)

19. Guida, F., Sandanger, T.M., Castagné, R., Campanella, G., Polidoro, S., Palli, D., Krogh, V., Tumino, R., Sacerdote, C., Panico, S., Severi, G., Kyrtopoulos, S.A., Georgiadis, P.,
Vermeulen, R.C.H., Lund, E., Vineis, P., Chadeau-Hyam, M.: Dynamics of smoking-induced genome-wide methylation changes with time since smoking cessation. Hum. Mol. Genet. 24(8), 2349 2359 (2015)

20. López-Otín, C., Galluzzi, L., Freije, J.M.P., Madeo, F., Kroemer, G.: Metabolic control of longevity. Cell. 166(4), 802-821 (2016)

21. Hanahan, D., Weinberg, R.A.: Hallmarks of cancer: the next generation. Cell. 144(5), 646-674 (2011)

22. Smith, M.T., Guyton, K.Z., Gibbons, C.F., Fritz, J.M., Portier, C.J., Rusyn, I., De Marini, D.M., Caldwell, J.C., Kavlock, R.J., Lambert, P., Hecht, S., Bucher, J.R., Stewart, B.W., Baan, R., Cogliano, V., Straif, K.: Key characteristics of carcinogens as a basis for organizing data on mechanisms of carcinogenesis. Environ. Health Perspect. 124(6), 713-721 (2016)

23. Gulliver, J., Morley, D., Dunster, C., McCrea, A., van Nunen, E., Tsai, M.Y., Probst-Hensch, N., Eeftens, M., Imboden, M., DucretStich, R., Naccarati, A., Galassi, C., Ranzi, A., Nieuwenhuijsen, M., Curto, A., Donaire-Gonzalez, D., Cirach, M., Vermeulen, R., Vineis, P., Hoek, G., Kelly, F.J.: Land use regression models for the oxidative potential of fine particles $\left(\mathrm{PM}_{2.5}\right)$ in five European areas. Environ. Res. 160, 247-255 (2018). https://doi.org/10.1016/j. envres.2017.10.002 